\title{
Construction and Functional Analysis of Luciferase Reporter Plasmid Containing GSNOR Gene Promoter
}

\author{
Zheng Deliang, Liao Xinghua, Wei Zhaoqiang, Du Fu, He Hongpeng, Zhang Tongcun \\ Key Laboratory of Industrial Microbiology \\ Tianjin University of Science and Technology \\ Tianjin, China \\ e-mail: slzdlzxy@163.com,xinghualiao@hotmail.com,Wzqkr713501@163.com,635053754@qq.com, \\ hehongpeng@tust.edu.cn,tony@tust.edu.cn
}

\begin{abstract}
S-nitrosoglutathione (GSNO) is a nitrosylating agent which mediates the posttranslational process of $\mathrm{S}$ nitrosylation on proteins resulting in modulation of their activity. GSNOR (S-Nitrosoglutathione reductase) is an enzyme related to GSNO degration, which has been used extensively in controlling S-nitrosylation levels in vivo. Myocardin is thought to have a key role in Vascular Smooth Muscle Cell (VSMC) development by acting on CArG-dependent genes. In this study, a human GSNOR promoter luciferase reporter construct was generated by PCR amplification of GSNOR promoter. The PCR fragment was digested and cloned into pGL3 vector. The promoter sequence was verified by sequencing. The results showed that luciferase reporter plasmids of GSNOR promoter were successfully constructed. Then the effects of a key transcription factor, which plays important roles in S-nitrosylation levels control, were investigated by luciferase reporter assays in VSMCs. The results showed that myocardin can enhance transcriptional activity of GSNOR. Our research will help us to screen some novel factors in regulating S-nitrosylation levels in vivo.
\end{abstract}

Keywords-GSNO; GSNOR; S-nitrosylation; luciferase activity assay

\section{INTRODUCTION}

S-Nitrosoglutathione (GSNO) reductase (GSNOR), also known as the human $\mathrm{ADH}$ class III enzyme and formaldehyde dehydrogenase [1], is a highly conserved enzyme that catalyzes the metabolism of the most abundant low molecular weight S-nitrosothiols (SNO), GSNO [2,3] and has been identified as a potential drug target for the treatment of a broad range of diseases [3-6]. GSNOR has been shown to be essential in vascular homeostasis and for survival during endotoxic challenge, underlining the important role that GSNOR plays in the cellular defence against nitrosative stress [2].

Myocardin, a coactivator of serum response factor (SRF), is highly expressed in embryonic cardiac and smooth muscle lineages plays a critical role in regulating smooth muscle cells phenotype switch [7,8]. Myocardin belongs to the SAP (SAF-A/B, Acinus, and PIAS) domain family of transcription factors and is a cardiac and smooth musclespecific expressed transcriptional coactivator of serum response factor (SRF) which binds to the CArG box
(CC[A/T]6GG) to regulate cardiac and smooth musclespecific genes [9].

In this study, GSNOR promoter was amplificated from human genome by PCR and inserted into pGL-3 (luciferase vector) basic vector successfully. Furthermore, luciferase assays were performed in VSMCs. The results showed that myocardin activates GSNOR promoter transcription. Our research will help us to screen some novel factors of VSMCs in regulating S-nitrosylation levels.

\section{Materials AND MethodS}

\section{A. Cell Culture}

Human Vascular smooth muscle cell(VSMC) line was obtained from American Type Culture Collection. VSMCs were grown in Dulbecco's modified Eagle's medium (DMEM) (GIBCO) supplemented with 10\% fetal bovine serum $(\mathrm{FBS})$ at $37^{\circ} \mathrm{C}$ in a $5 \% \mathrm{CO}_{2}$ incubator.

\section{B. Plasmid Construction}

The human genome was extracted from VSMCs. GSNOR promoter fragment from -1263 to +90 is amplified by PCR using the primers (F: 5'CGAGGTACCCAGAAATCCAGTAGGCAGTT -3'; R: 5'- TATACGCGTATGTTCACGGATTCTGGTCG -3'). PCR condition is as follows: Pre-degeneration for $5 \mathrm{~min}$ at $94^{\circ} \mathrm{C}$, denaturation for 1 minute at $94^{\circ} \mathrm{C}$, annealing for 1 min at $56^{\circ} \mathrm{C}$, and extension for 1.5 minute at $72^{\circ} \mathrm{C}$. PCR reaction was carried out for 35 cycles and PCR products were visualized in $2 \%$ agarose gels stained with ethidium bromide under UV transillumination.

The PCR product and pGL3-Basic vehicle plasmid were digested with restriction enzyme $\mathrm{KpnI}$ and $\mathrm{MluI}$ at $37^{\circ} \mathrm{C}$ for 1h. The fragment of PCR product and pGL3-Basic vehicle plasmid were mixed with $2 \mu \mathrm{L}$ T4 ligase buffer and $1 \mu \mathrm{L}$ T4 DNA ligase and added water to $20 \mu \mathrm{L}$, incubated at $16^{\circ} \mathrm{C}$ for $24 \mathrm{~h}$, and then transformed into competent E.coli. Monoclonal colony was well separated by incubating in 5 $\mathrm{mL}$ LB which contains ampicillin at $37^{\circ} \mathrm{C}$ overnight. A monoclonal colony was picked and cultured in LB. The plasmid was extracted with the small extraction of plasmid kit (Solarbio) according to the manufacturer's instructions and sequenced. 


\section{Luciferase Reporter Assays}

18 hours after transfection, $50 \mu \mathrm{L}$ of protein extracts $(100$ $\mu \mathrm{L} /$ well) were prepared for luciferase assays, which were measured by using a luciferase reporter assay system (Promega) on a Synergy ${ }^{\mathrm{TM}} 4$ (Bioteck). All experiments were performed at least three times with different preparations of plasmids and primary cells, producing qualitatively similar results.

\section{RESUlt}

\section{A. Construction of GSNOR Promoter Luciferase Reporter Plasmid}

To estimate the PCR amplification of GSNOR promoter, agarose gel electrophoresis was performed. As shown in Figure1, a single band emerged at the site of 1354bp, which represents the PCR products of GSNOR promoter.

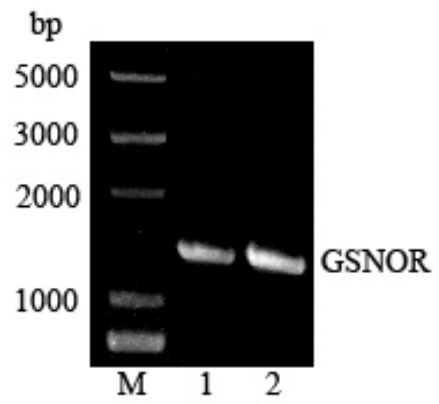

Figure 1. Agarose gel electrophoretic analysis of PCR product.

$$
\text { 1-2: GSNOR gene promoter. }
$$

Then, the PCR product was digested by double restriction enzymes and cloned to the pGL3-Basic vector. After that, the recombinant plasmid was extracted and purified, and the agarose gel electrophoretic analysis was performed. Figure 2 showed the size of recombinant plasmid that was purified.

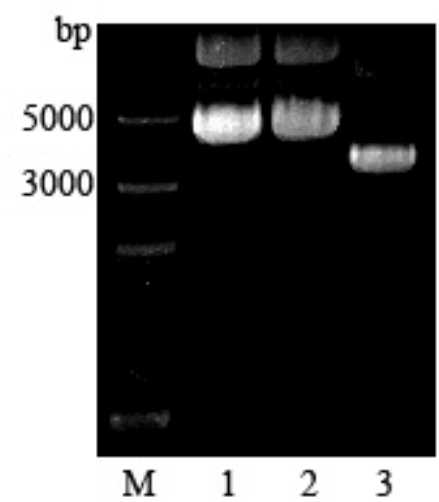

Figure 2. Agarose gel electrophoretic analysis of plasmids. 1-2: recombinant plasmid 3: pGL3-Basic vehicle plasmid;

To confirm the recombinant plasmids, we used double restriction enzymes to digest them and then electrophoresed through agarose gel. As shown in Figure3, the recombinant plasmid was cut into two bands. One band was at about 1,354 bp, which represents GSNOR promoter, and another band was at 5,000 bp, which represents pGL3-Basic vehicle plasmid. The luciferase reporter plasmid of GSNOR gene promoter was further confirmed by sequencing. The result of DNA sequence alignment showed that luciferase reporter plasmid containing GSNOR promoter was constructed successfully.

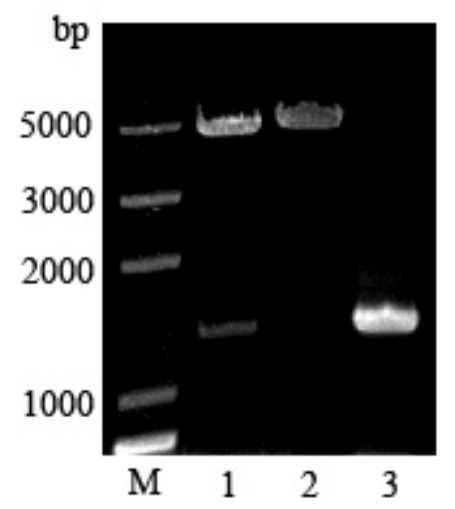

Figure 3. Agarose gel electrophoretic analysis of plasmids. 1: recombinant plasmid; 2: pGL3-Basic vehicle plasmid; 3: GSNOR gene promoter.

\section{B. Fluorescence of the Efficiency of Transduction}

The transfection efficiency was demonstrated using a EGFP (enhanced green fluoresent protein) expression plasmid. As shown in Figure4, the transfection efficiency was approximately $60 \%$, demonstrating that DNA was transfected efficiently into VSMCs.

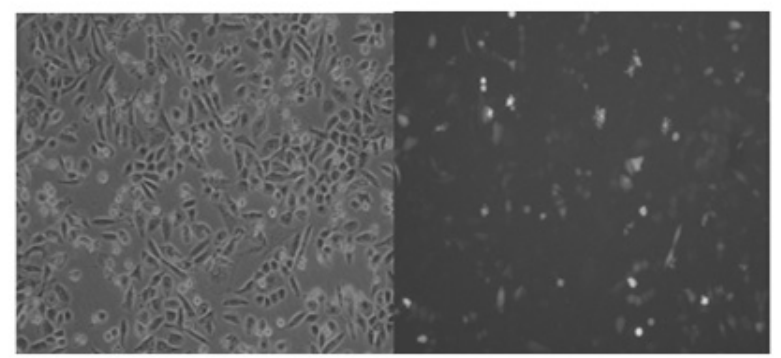
(a) Morphology
(b) GFP fluorescence

Figure 4. The transfection efficiency of VSMCs

\section{Luciferase Assay}

1) Myocardin can enhance the transcriptional activity of GSNOR promoter obviously

Luciferase Reporter Assays were performed after VSMCs were transfected with myocardin and GSNOR promoter. Contrasting with control group transfected with pcDNA3.1, myocardin showed a significant effect to enhance the transcription activity of GSNOR promoter (Figure5). 


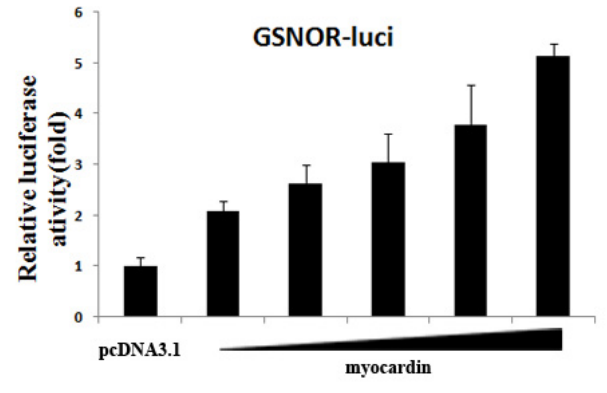

Figure 5. Myocardin can enhance the transcriptional activity of GSNOR.

\section{DisCUSSION}

GSNOR is a Class III ADH encoded by the ADH 5 gene in humans and GSNOR is also referred to as formaldehyde dehydrogenase which oxidizes S-hydroxymethylglutathione. GSNOR was recently shown to be the major enzyme that catabolizes GSNO [1,9] by converting GSNO to S-hydroxylamino-glutathione [10]. Importantly, GSNOR shows specificity toward GSNO rather than other substrates $[1,10]$. GSNO is one of the major, biologically stable nitric oxide (NO) adducts of cysteine containing peptides and proteins [11].

GSNO is an efficient agent of protein trans-nitrosylation and thus plays a critical role in maintaining the balance of SNOs. S-nitrosylation is an important biological reaction of nitric oxide and refers to the conversion of thiol groups, including cysteine residues in proteins, to form S-nitrosothiols [12]. GSNOR could catalyze the reduction of GSNO $[3,4]$ to the unstable intermediate S(N-hydroxyamino)glutathione to control the balance of Snitrosylation lelevs [13].

Myocardin was originally identified as a serum response factor (SRF) co-factor expressed only in cardiomyocytes and smooth muscle cells [14]. Myocardin increases activation of SRF-dependent genes by forming a higher order complex with SRF and facilitating its association with its CArG box DNA binding domain. Transcriptional activation is promoted by a variety of mechanisms including myocardin's own powerful transcriptional activation domain [15].

In this study, we cloned GSNOR promoter luciferase reporter plasmid successfully and found that myocardin could enhance the transcriptional activity of GSNOR promoter. Our findings support the premise from the transcriptional level that myocardin can increase the ability of GSNO degradation in VSMCs. Our research will help us to screen some novel factors in regulating $\mathrm{S}$-nitrosylation levels in vivo.

\section{ACKNOWLEDGMENT}

This work was financially supported by National Natural Science Foundation of China (No. 30970615, 31071126, 31000343, 31171303, 31171297, 31501149)), Program for Changjiang Scholars and Innovative Research Team in University of Ministry of Education of China (IRT1166),
Research Fund for the Doctoral Program of Higher Education of China (20111208110001) and the Key Project of Chinese Ministry of Education (212010).

\section{REFERENCES}

[1] L. Uotila, and M. Koivusalo, "Formaldehyde dehydrogenase from human liver, purification, properties, and evidence for the formation of glutathione thiol esters by the enzyme," J Biol Chem, vol 10, Dec. 1974, pp. 7653-63.

[2] L. Liu, Y. Yan, M. Zeng, J. Zhang, M.A. Hanes, G. Ahearn, T.J. McMahon , et al, "Essential roles of S-nitrosothiols in vascular homeostasis and endotoxic shock," Cell, vol 110, Feb. 2004, pp. $617-28$.

[3] D.E. Jensen, G.K. Belka, and B. Du. "S-nitrosoglutathione is a substrate for rat alcohol dehydrogenase class III isoenzyme," Biochem J, vol 331, Apr. 1998, pp. 659-68.

[4] J.M. Fukuto, M.D. Bartberger, A.S. Dutton, N. Paolocci, D.A. Wink, and K.N. Houk. "The physiological chemistry and biological activity of nitroxyl (HNO): the neglected, misunderstood, and enigmatic nitrogen oxide," Chem Res Toxicol. vol 18, May, 2005, pp. 790-801.

[5] B. Gaston, J. Reilly, J.M. Drazen, J. Facklert, P. Ramdev, D. Arnelle, et al, "Endogenous nitrogen oxides and bronchodilator Snitrosothiols in human airways," Proc Natl Acad Sci USA. vol 90, Dec. 1993, pp. 10957-61.

[6] D.T. Hess, A. Matsumoto, S.O. Kim, H.E. Marshall, and J.S. Stamler. "Protein S-nitrosylation: purview and parameters," Nat Rev Mol Cell Biol, vol. 6, Feb. 2005, pp. 150-66.

[7] D. Wang, P.S. Chang, Z. Wang, L. Sutherl and J.A. Richardson , E Small, et al.,"Activation of cardiac gene expression by myocardin, a transcriptional cofactor for serum response factor," Cell, vol 105, Jun. 2001, pp. 851-62.

[8] W. Xing, T.C. Zhang, D. Cao, Z. Wang, C.L. Antos,S. Li_, et al. , "Myocardin induces cardiomyocyte hypertrophy," Circ Res, vol 98, Apr. 2006, pp. 1089-97.

[9] K.G. Shyu, W.P. Cheng, and B.W. Wang, “Angiotensin II downregulates mircroRNA-145 to regulate Kruppel-like factor 4 and myocardin expression in human coronary arterial smooth muscle cells under high glucose conditions," Mol Med. Jul. 2015, doi: 10.2119/molmed.2015.00041.

[10] X. Sun, J. Qiu, S.A. Strong, L.S. Green, J.W. Wasley, J.P. Blonder,et al., "Discovey of potent and novel S-nitrosoglutathione reductase inhibitors devoid of cytochrome P450 activities," Bioorg Med Chem Lett. vol 21, Oct.2011, pp. 5849-53, doi: 10.1016/j.bmcl.2011.07.103.

[11] W. Wei, B. Li, M.A. Hanes, S. Kakar, X. Chen, and L. Liu. "Snitrosylation from GSNOR deficiency impairs DNA repair and promotes hepatocarcinogenesis," Sci Transl Med, vol 2, Feb. 2010, pp. 19ra13, doi: 10.1126/scitranslmed.3000328.

[12] S. Giri, R. Rattan, M. Deshpande, J.L. Maguire, Z. Johnson, R.P. Graham ,et al., "Preclinical therapeutic potential of a nitrosylating agent in the treatment of ovarian cancer," PLoS One, vol 9, Jun.2014, pp. e97897, doi: 10.1371/journal.pone.0097897. eCollection 2014.

[13] X. Sun, J. Qiu, S.A. Strong, L.S. Green, J.W. Wasley, J.P. Blonder, et al., "Structure-activity relationship of pyrrole based Snitrosoglutathione reductase inhibitors: Carboxamide modification," Bioorg Med Chem Let - t, vol 22, Mar.2012, pp. 2338-42, doi: 10.1016/j.bmcl.2012.01.047. Epub 2012 Feb 2.

[14] D. Cao, C. Wang, R. Tang, H. Chen, Z. Zhang, M. Tatsuguchi, et al., "Acetylation of myocardin is required for the activation of cardiac and smooth muscle genes," J Biol Chem, vol 287, Nov. 2012, pp. 38495-504, doi: 10.1074/jbc.M112.353649. Epub 2012 Sep 23.

[15] L .Raphel, A. Talasila, C. Cheung, and S. Sinha. "Myocardin is thought to have a key role in smooth muscle cell (SMC) development 
International Conference on Materials Chemistry and Environmental Protection (MEEP 2015)

by acting on CArG-dependent genes," PLoS One, vol 7, 2012; pp. e44052, doi: 10.1371/journal.pone.0044052. Epub 2012 Aug 28. 